Journal of Zhejiang University-SCIENCE A (Applied Physics \& Engineering) ISSN 1673-565X (Print); ISSN 1862-1775 (Online)

www.zju.edu.cn/jzus; www.springerlink.com

E-mail: jzus@zju.edu.cn

Editorial:

\title{
Environmental risks of engineered nanomaterials
}

\author{
Kun YANG, Guest Editor-in-Chief \\ Dao-hui LIN, Guest Editor \\ (Department of Environmental Science, Zhejiang University, Hang- \\ zhou 310058, China; Zhejiang Provincial Key Laboratory of Organic \\ Pollution Process and Control, Hangzhou 310058, China) \\ E-mail: kyang@zju.edu.cn; lindaohui@zju.edu.cn
}

doi:10.1631/jzus.A1400219

Ordinary materials such as carbon and silicon, when reduced to a nanoscale, often exhibit novel and unpredictable characteristics such as extraordinary strength, chemical reactivity, electrical conductivity, or other characteristics that the same material does not possess at micro or macro scales (Aitken et al., 2004). When devices are fabricated with these materials in nanoscale, their properties and applications expand enormously. The new and invisibly tiny materials, nanomaterials, are revolutionizing many industries and are set to have dramatic and fundamental impacts across the fields of physics, chemistry, biology, material science, and engineering. For example, the flower-like $\alpha-\mathrm{Fe}_{2} \mathrm{O}_{3}$ nanostructures, reported in this special issue by Xie et al. (2014), were suggested as suitable materials in wastewater treatment due to their excellent adsorption for $\mathrm{As}(\mathrm{V})$ and their high photocatalytic performance for methylene blue photodegradation. A wide range of nanomaterials have already been produced including carbon nanotubes (CNTs) and buckyballs, nanowires, nano-oxides, and metal nanomaterials. According to an early report made by The Royal Society \& The Royal Academy of Engineering in 2004, the quantities of nanomaterials used in the marketplace amounts to $1000-2000$ tons per annum worldwide in 2004, which will expand to 10000-100000 tons in 2011-2020 (http://www. nanotec.org.uk/finalReport.htm). A recent inventory (http://www.nanotechproject.org/cpi/) reported that

(C) Zhejiang University and Springer-Verlag Berlin Heidelberg 2014 more than 1600 of nanotechnology-based consumer products are currently available in the marketplace. Therefore, nanotechnology is considered to be one of the world's most promising new technologies of the 21 st Century, which is attracting increasing investment from governments and industries, all around the world.

As well as the benefits from nanotechnology, the debate has already started on the new health and environmental risks that nanotechnology might bring and whether the environmental and social costs of nanotechnology outweigh its many benefits (Brumfiel, 2003; Colvin, 2003; Service, 2003), since signs of toxicity and damage of CNTs to lung tissue in mice was observed (Lam et al., 2004; Warheit et al., 2004) and nanomaterials, especially their particles, will inevitably enter the environment during their production, transport, handling, use, and disposal (Gottschalk and Nowack, 2011). "There are issues of risk with every new technology and it would be silly to think we have nothing to consider", said Vicki COLVIN, a chemist at Rice University (Service, 2003). Therefore, it is important to keep our eyes open for the potential health and environmental risks of nanomaterials and face this now rather than after nanotechology becomes widespread.

Today, 10 years later, after the first report of the toxicity and damage of CNTs (Lam et al., 2004; Warheit et al., 2004), exposure and toxicity of nanoparticles, including not only CNTs but also other forms, to animals, microbes, plants, and their tissues such as cells has been widely investigated (Miralles et al., 2012; Sharifi et al., 2012; Podila and Brown, 2013). Several mechanisms such as the production of intracellular oxidative stress, mechanistic damage, and changes in nutrient elements levels were suggested based on the experimental observations to interpret the toxicity and damage of nanoparticles to animals, microbes, and plants (Miralles et al., 2012; Sharifi et al., 2012; Podila and Brown, 2013; Deng et al., 2014). 
Besides the toxicity, emission, occurrence, behaviors such as transport and transformation, and fate of nanoparticles in the environment are also widely investigated to help the assessment of the potential health and environmental risks of nanomaterials because they are directly related to the exposure of nanoparticles to animals, microbes, and plants in the environment and thus affect their toxicity and damage (Nowack and Bucheli, 2007; Lin et al., 2010). For example, the sorption of toxic chemicals by nanoparticles in the environment could enhance the bioavailability and mobility of pollutants into organisms and thus add additional toxicity to that of nanoparticles when these nanoparticles are taken up by and accumulated in organisms (Yang and Xing, 2010). This sorption behavior could also reduce the bioavailability and mobility of pollutants into organisms and thus enhance their persistence in the environment if nanoparticles cannot be taken up by or accumulated in the organisms (Yang and Xing, 2010). Although more and more information and empirical data regarding the potential toxicity and environmental behaviors of nanoparticles are available with the rapidly increasing researches conducted in the past 10 years, current knowledge and empirical data are still far away for the comprehensive understanding and the accurate estimation of health and environmental risks associated with nanoparticles, because the natural environment is a much more complex system. The study in this field is still new. Debates widely exist in literature. A number of knowledge gaps and challenges are still waiting to be addressed (Sharifi et al., 2012; Podila and Brown, 2013; Deng et al., 2014; Luo et al., 2014; Kumar et al., 2014).

In this special issue, we invited primary scientists on the leading edge in this field with recent high impact research works to share their expertise and perspectives. The collected papers cover various topics, such as the measurement and characteristics of engineered nanoparticles in the environment, toxicities of nanoparticles to organisms, complex behaviors of nanoparticles with contaminants in the environment, and fate, transformation, and transport of nanoparticles in the environment.

In this special issue, Luo et al. (2014) provided a critical review of the current knowledge on worldwide production, measured environmental concentrations and available analyzing and characterizing techniques of engineered $\mathrm{TiO}_{2}$ nanoparticles in the environment. They concluded in this review that analytical methods currently used for engineered nanoparticles in the environment cannot as yet provide sufficiently reliable data, which results in a serious lack of information about their occurrence in the environment. They also suggested that, before new techniques are being developed, the current analytical techniques have to be combinedly used, accompanied by careful sample preparation, in such a way, that data validation is possible. Wang and Wang (2014) summarized the dissolution behaviors of three common metallic-based nanoparticles including nano- $\mathrm{ZnO}$, nano- $\mathrm{Ag}$, and nano- $\mathrm{TiO}_{2}$ and their toxicities to algae, zooplankton, and fish in toxicological studies. A kinetic model was developed to evaluate the contribution of dissolved ions to the total accumulation of nanoparticles and to interpret the reported toxicological data. This review emphasized the importance of integrating physicochemical kinetics and uptake kinetics in evaluating the bioavailability and toxicity of nanoparticles. Deng et al. (2014) reviewed the literature on nanoparticle uptake, translocation/ distribution, and generational transmission in various crop species, as well as potential material trophic transfer. They noted that (1) cultivation of crops in nanoparticle contaminated environments has unknown implications for food safety and quality, (2) mechanisms underlying nanoparticle phytotoxicity and bioavailability are unclear, and (3) developing novel techniques for in vivo identification/ characterization of nanoparticles are critically needed. Peng et al. (2014) provided a systematical review on sorption mechanisms and impact parameters of organic contaminants on CNTs. From the information in various literature, they worried that dispersed CNTs may result in higher health and environmental risks than undispersed ones when they are released into the environment because dispersed CNTs could expose more sorption sites and thus enhance the adsorption of organic contaminants. The four critical reviews will help the journal readers for the comprehensive understanding of the research advances in the respective fields. Knowledge gaps and challenges in these research fields were listed clearly in these reviews, encouraging future research studies. Given the abundance of uncertainty in the literature summarized by the four reviews, it is clear that more research is 
urgently needed in these areas, only then, can one accurately assess the exposure, risk, and overall implications for food safety and also enable guidance development for the sustainable implementation of nanotechnology (Deng et al., 2014).

A first report of the genotoxic potential of $\mathrm{TiO}_{2}$ nanoparticles on hydroponically cultivated zucchini (Cucurbita pepo), observed using a random amplified polymorphic DNA (RAPD) technique, was reported by Moreno-Olivas et al. (2014) in this special issue. This report opens a window to future research studies in the toxicity of nanoparticles for the readers. Cui et al. (2014) reported that the toxicity of nano-Ag to plants (i.e., cucumber and wheat) was possibly due to the release of $\mathrm{Ag}^{+}$from nano-Ag rather than the bulk nano-Ag itself. They observed that, cysteine, a strong chelating ligand of $\mathrm{Ag}^{+}$, could completely eliminate the effects of nano-Ag on cucumber and wheat. This study will help the understanding of the importance of dissolved ions in evaluating the bioavailability and toxicity of metallic-based nanomaterials.

A systematical investigation was conducted by Wang et al. (2014) to examine the adsorption of tetracycline, a commonly used antibiotic with relatively complex structures, to functionalized CNTs, and to understand the effects of metal ions, $\mathrm{Cu}(\mathrm{II})$, and $\mathrm{Ni}(\mathrm{II})$, on the adsorption. They observed that functionalized CNTs, compared with un-functionalized ones, can exhibit significantly different adsorption for organic pollutants, as this is largely dependent on the types and abundance of functionalities on the CNTs surfaces. The influence of coexisted $\mathrm{Cu}(\mathrm{II})$ and $\mathrm{Ni}(\mathrm{II})$ on the adsorption of un-functionalized CNTs for tetracycline is negligible, but it is significant on the functionalized ones. These observations are important for the understanding of the environmental risks of CNTs and/or bioavailability of the environmental contaminants since organic contaminants often coexist with heavy metal ions in the environment and surface functionalization such as by oxidation is commonly done in the synthesis and purification of CNTs and occurs in the environment.

Dissolved organic matter (DOM), bovine serum albumin (BSA), and surfactants, which are ubiquitous in the environment and are used to prepare stable suspensions of nanoparticles with the assistance of sonication dispersion, were considered to enhance the colloidal stability of the nanoparticles in the envi- ronment and thus make the nanoparticles travel in longer distances to pose environmental risks in a larger region. For example, BSA treatment was observed to enhance the colloidal stability of $\mathrm{Al}_{2} \mathrm{O}_{3}$, $\mathrm{SiO}_{2}$, and $\mathrm{TiO}_{2}$ nanoparticles in $\mathrm{Na}^{+}$and $\mathrm{Ca}^{2+}$ solutions, while DOM treatment decreased the stability greatly in $\mathrm{Ca}^{2+}$ solution (Hu et al., 2014). Similar phenomenon was observed for the stablized $\mathrm{C}_{60}$ suspension (Zhang et al., 2014), i.e., DOM could enhance the colloidal stability in $\mathrm{Na}^{+}$solution but decrease the stability significantly in $\mathrm{Ca}^{2+}$ and $\mathrm{La}^{3+}$ solutions. However, we observed that single-walled CNTs (SWCNTs) powders could not be stabilized in water even in the presence of surfactants, without the assistance of extreme agitation such as by sonication in dispersion (Yang et al., 2014). $\mathrm{C}_{60}$ powders were also observed unable to be stably suspended in water or in DOM solution even with the assistance of sonication in dispersion (Zhang et al., 2014). Moreover, the stably suspended nanoparticles may not remain stable in the presence of environmentally relevant cations (e.g., $\mathrm{Na}^{+}, \mathrm{K}^{+}, \mathrm{Ca}^{2+}, \mathrm{Mg}^{2+}$, and $\mathrm{La}^{3+}$ ) (Hu et al., 2014; Yang et al., 2014; Zhang et al., 2014), especially once they were diluted (Yang et al., 2014). Dilution is a process commonly occurring once contaminants are released into the environment. Therefore, nanoparticles such as bulk SWCNTs will not travel long distances in significant concentrations in the natural environment (Yang et al., 2014). The results of dispersion experiments using vigorous sonication could be inappropriate for assessing and predicting the dispersion and suspension of bulk CNTs in the aqueous environment because sonication induces more extreme agitation than that is encountered in the natural aqueous environment (Yang et al., 2014). Multi-walled CNTs with bigger diameters than $\mathrm{C}_{60}$ and SWCNTs could be much easier to be dispersed and suspended stably in water because of lower sonication energy needed in dispersion (Yang et al., 2013), and thus could travel longer distances in the environment and pose greater risks.

We hope that the most up-to-date view of these scientists shared in this special issue would move the frontier of science a litter further forward and improve our understanding of the environmental risks of nanoparticles in general. We also hope these cutting edge articles will promote discussions among established scientists and provide benefits for the journal readers. 


\section{References}

Aitken, R.J., Creely, K.S., Tran, C.L., 2004. Nanoparticles: An Occupational Hygiene Review. HSE (Health and Safety Executive) Research Report 274.

Brumfiel, G., 2003. Nanotechnology: a little knowledge. Nature, 424(6946):246-248. [doi:10.1038/424246a]

Colvin, V.L., 2003. The potential environmental impact of engineered nanomaterials. Nature Biotechnology, 21(10): 1166-1170. [doi:10.1038/nbt875]

Cui, D., Zhang, P., Ma, Y.H., et al., 2014. Phytotoxicity of silver nanoparticles to cucumber (Cucumis sativus) and wheat (Triticum aestivum). Journal of Zhejiang University-SCIENCE A (Applied Physics \& Engineering), 15(8):662-670. [doi:10.1631/jzus. A1400114]

Deng, Y.Q., White, J.C., Xing, B.S., 2014. Interactions between engineered nanomaterials and agricultural crops: implications for food safety. Journal of Zhejiang University-SCIENCE A (Applied Physics \& Engineering), 15(8):552-572. [doi:10.1631/jzus.A1400114]

Gottschalk, F., Nowack, B., 2011. The release of engineered nanomaterials to the environment. Journal of Environmental Monitoring, 13(5):1145-1155. [doi:10.1039/ c0em00547a]

Hu, F.B., Lin, Y.F., Chen, R., et al., 2014. Effects of humic acid and bovine serum albumin on the agglomeration and sedimentation of oxide nanoparticles. Journal of Zhejiang University-SCIENCE A (Applied Physics \& Engineering), 15(8):643-652. [doi:10.1631/jzus.A1400138]

Kumar, A., Kumar, P., Anandan, A., et al., 2014. Engineered nanomaterials: knowledge gaps in fate, exposure, toxicity, and future directions. Journal of Nanomaterials, 2014: 130198. [doi:10.1155/2014/130198]

Lam, C.W., James, J.T., McCluskey, R., et al., 2004. Pulmonary toxicity of single-wall carbon nanotubes in mice 7 and 90 days after intratracheal instillation. Toxicological Sciences, 77(1):126-134. [doi:10.1093/ toxsci/kfg243]

Lin, D.H., Tian, X.L., Wu, F.C., et al., 2010. Fate and transport of engineered nanomaterials in the environment. Journal of Environment Quality, 39(6):1896-1908. [doi:10.2134/ jeq2009.0423]

Luo, Z.X., Wang, Z.H., Xu, B., et al., 2014. Measurement and characterization of engineered titanium dioxide nanoparticles in the environment. Journal of Zhejiang UniversitySCIENCE A (Applied Physics \& Engineering), 15(8): 593-605. [doi:10. 1631/jzus.A1400115]

Miralles, P., Church, T.L., Harris, A.T., 2012. Toxicity, uptake, and translocation of engineered nanomaterials in vascular plants. Environmental Science \& Technology, 46(17): 9224-9239. [doi:10.1021/es202995d]

Moreno-Olivas, F., Gant, V.U.Jr., Johnson, K.L., et al., 2014. Random amplified polymorphic DNA reveals that $\mathrm{TiO}_{2}$ nanoparticles are genotoxic to Cucurbita pepo. Journal of Zhejiang University-SCIENCE A (Applied Physics \& Engineering), 15(8):618-623. [doi:10.1631/jzus.A1400159]

Nowack, B., Bucheli, T.D., 2007. Occurrence, behavior and effects of nanoparticles in the environment. Environmental Pollution, 150(1):5-22. [doi:10.1016/j.envpol.2007.06. 006]

Peng, H.B., Zhang, D., Li, H., et al., 2014. Organic contaminants and carbon nanoparticles: sorption mechanisms and impact parameters. Journal of Zhejiang UniversitySCIENCE A (Applied Physics \& Engineering), 15(8): 606-617. [doi:10.1631/jzus.A1400112]

Podila, R., Brown, J.M., 2013. Toxicity of engineered nanomaterials: a physicochemical perspective. Journal of Biochemical and Molecular Toxicology, 27(1):50-55. [doi:10.1002/jbt.21442]

Service, R.F., 2003. American Chemical Society meeting. Nanomaterials show signs of toxicity. Science, 300(5617): 243. [doi:10.1126/science.300.5617.243a]

Sharifi, S., Behzadi, S., Laurent, S., et al., 2012. Toxicity of nanomaterials. Chemical Society Reviews, 41(6):23232343. [doi:10.1039/c1cs15188f]

Wang, J., Wang, W.X., 2014. Significance of physicochemical and uptake kinetics in controlling the toxicity of metallic nanomaterials to aquatic organisms. Journal of Zhejiang University-SCIENCE A (Applied Physics \& Engineering), 15(8):573-592. [doi:10.1631/jzus.A1400109]

Wang, Z.Y., Duan, L., Zhu, D.Q., et al., 2014. Effects of Cu(II) and $\mathrm{Ni}(\mathrm{II})$ ions on adsorption of tetracycline to functionalized carbon nanotubes. Journal of Zhejiang UniversitySCIENCE A (Applied Physics \& Engineering), 15(8): 653-661. [doi:10.1631/jzus.A1400108]

Warheit, D.B., Laurence, B.R., Reed, K.L., et al., 2004. Comparative pulmonary toxicity assessment of singlewall carbon nanotubes in rats. Toxicological Sciences, 77(1):117-125. [doi:10.1093/toxsci/kfg228]

Xie, K., Wang, X.X., Liu, Z.J., et al., 2014. Synthesis of flower-like $\alpha-\mathrm{Fe}_{2} \mathrm{O}_{3}$ and its application in wastewater treatment. Journal of Zhejiang University-SCIENCE A (Applied Physics \& Engineering), 15(8):671-680. [doi:10. 1631/jzus.A1400133]

Yang, K., Xing, B.S., 2010. Adsorption of organic compounds by carbon nanomaterials in aqueous phase: polanyi theory and its application. Chemical Reviews, 110(10):59896008. [doi:10.1021/cr100059s]

Yang, K., Yi, Z.L., Jing, Q.F., et al., 2013. Sonication assisted dispersion of carbon nanotubes in the aqueous solution of the anionic surfactant SDBS: the role of sonication energy. Chinese Science Bulletin, 58(17):2082-2092. [doi:10. 1007/s11434-013-5697-2]

Yang, K., Yi, Z.L., Jing, Q.F., et al., 2014. Dispersion and aggregation of single-walled carbon nanotubes in aqueous solutions of anionic surfactants. Journal of Zhejiang University-SCIENCE A (Applied Physics \& Engineering), 15(8):624-633. [doi:10.1631/jzus.A1400113]

Zhang, L.Q., Zhang, Y.K., Lin, X.C., et al., 2014. The role of humic acid in stabilizing fullerene $\left(\mathrm{C}_{60}\right)$ suspensions. Journal of Zhejiang University-SCIENCE A (Applied Physics \& Engineering), 15(8):634-642. [doi:10.1631/jzus. A1400115] 


\section{中文䠶要:}

\section{本文题目：人造纳米材料的环境风险}

Environmental risks of engineered nanomaterials

本文概要: 随着纳米技术的发展和纳米材料的大量开发生产及使用, 纳米颗粒排放到环境可能产生的健 康和环境风险开始引起广泛的关注, 已经成为当前环境领域研究的热点。纳米颗粒的风险不 仅来自它们的生物毒性, 也与它们在环境中的浓度、形态、迁移转化过程及环境的复杂条件 密切相关。自从发现纳米颗粒的生物毒性至今已十年，大量的相关研究工作已经促进了对纳 米颗粒风险的了解, 但距离全面掌控和准确评价它们的风险尚存在很大的距离。研究瓶颈如 缺乏有效的研究技术手段、研究结果的不确定性、研究结果自相矛盾等普遍存在, 是当前研 究的挑战。本专辑收集了在该研究领域具有影响力的研究人员的最新研究成果和思考, 介绍 该领域的最新研究进展, 希望能帮助读者了解相关研究工作并促进研究人员开展讨论, 进一 步推进该研究领域和纳米技术的持续发展。

关键词组: 纳米颗粒; 毒性; 环境行为; 环境风险

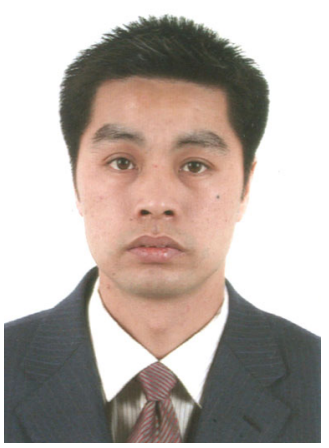

Dr. Kun YANG, Guest Editor-in-Chief

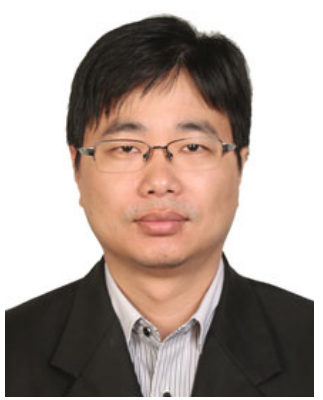

Dr. Dao-hui LIN Guest Editor
Dr. Kun YANG is a new Associate Editor-in-Chief of Zhejiang University-SCIENCE A (Applied Physics \& Engineering) in 2014. He received his BS degree in 1999 and his $\mathrm{PhD}$ degree in 2004 in Environmental Science from Zhejiang University, China. In 2004, he joined Zhejiang University, where he is an active faculty member in teaching and research and was promoted to associate professor and full professor in 2006 and 2010, respectively. Dr. YANG was a postdoctoral fellow from 2005 to 2006 at the University of Massachusetts, Amherst, USA. He won the second prize of the Natural Science Award in University of China in 2007, the first prize of the Zhejiang Provincial Science and Technology Award of China in 2010, the first prize of the Science and Technology Award in the University of China in 2012, and the second prize of the State Natural Science Award of China in 2013. He was selected as a New Century Excellent Talent in University by the Ministry of Education of China in 2008 and as an Excellent Young Talent in environmental science and technology by the Environmental Protection Agency of China in 2013. His research work has been supported by the China National Funds for Excellent Young Scientists since 2013. As an author and coauthor, Dr. YANG has published more than 60 articles in refereed technical journals and his publications are frequently cited by his peers; his research work is ranked in the top $1 \%$ of cited authors for journals in environmental sciences and ecology. His current research interests focus on the environmental behavior and toxicity of engineered nanomaterials, the sorption and fate of organic chemicals in soils and sediments, the synthesis and characterization of porous adsorbents, and the remediation of contaminated soils.

Dr. Dao-hui LIN is a professor of Environmental Chemistry (since 2009) at Zhejiang University, where he has been involved in teaching and research since 1998 . He received his MS degree from Beijing Normal University (1998) and PhD degree from Zhejiang University (2005), China. He was a visiting scholar (2006-2008) at the University of Massachusetts at Amherst, USA, and was selected as a New Century Excellent Talent in University by the Ministry of Education of China in 2010. His current research interests focus on environmental behavior and risks of contaminants, especially of engineered nanomaterials. He has published 63 peer-reviewed articles. 